\title{
Nasal scale: a novel supplemental preoperative airway assessment technique
}

\author{
Habib Bostan ${ }^{*}$, Yakup Tomak ${ }^{2}$, Başar Erdivanli ${ }^{3}$ and Leyla Karaoglu ${ }^{4}$
}

*Correspondence: d.h.bostan@gmail.com

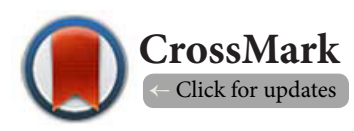

\begin{abstract}
'The Ministry of Justice, Council of Forensic Medicine, Istanbul, Turkey.
2Department of Anesthesiology and Reanimation, Faculty of Medicine, Sakarya University, Sakarya, Turkey.

${ }^{3}$ Department of Anesthesiology and Reanimation, Faculty of Medicine, Recep Tayyip Erdogan University, Rize, Turkey.

${ }^{4}$ Department of Public Health, Faculty of Medicine, Recep Tayyip Erdogan University, Rize, Turkey.
\end{abstract}

\begin{abstract}
Aim and background: The aim of the study is to investigate whether there is a relationship between difficult intubation and the structure of the nose in Eastern Black Sea Region of Turkey, where a higher incidence of difficult intubation in humans with typical nose structure is observed.

Materials and methods: Patients older than 18 years of age and having a physical ASA score of I-III were included in the study. Emergency and obstetrics cases, patients with a history of nasal trauma, nasal operation or airway anomaly, and patients lacking teeth were excluded from study. A total of 500 patients fulfilling these criteria were enrolled in the study. A novel nasal scale was developed as an objective bedside method to measure the prediction of difficult intubation. We compared the nasal scale's ability to predict difficult intubation with available predictive tests. 500 patients scheduled for elective general anesthesia were evaluated preoperatively using the NS, MP, TRMD and SMD methods. Cormack and Lehane grades III and IV were accepted as difficult intubation.

Results: The value for the area under the ROC curve was 0.63 for NS. The specificity of NS (93.6\%) was found to be higher than SMD and TRMD (89\% and 71.2\%, p<0.001; respectively) and lower than MP $(97.9 \%$; $<<0.05)$. The accuracy of NS $(85.8 \%)$ was higher than SMD and TRMD $(69 \%$ and $82.8 \%$, respectively) and lower than MP (96\%).

Conclusions: The NS is an objective and specific test that can be easily applied and can supplement the existing tests.
\end{abstract}

Keywords: Nose, scoring system, mallampati, thyromental distance, sternomental distance, difficult intubation

\section{Introduction}

Tracheal intubation with direct laryngoscopy is vital for dealing with the general anesthesia of patients undergoing surgery. In the most of cases, direct laryngoscopy can visualize the larynx and glottis conveniently, on the other hand in some cases, the unpredicted obscurity occurs during intubation leading morbidity and mortality associated with anesthetic practice $[\mathbf{1 , 2}]$. The reported incidence of difficult laryngoscopy and tracheal intubation varies from $0.01 \%$ to $13 \%$ in patients undergoing surgery $[1,3]$.

There have been many attempts to predict difficult intubation during preoperative assessment using a simple bedside physical examination [4]. Methods used to predict difficult intubation include Mallampati classification (MP), thyromental distance (TRMD), sternomental distance (SMD), and radiography of head and neck. In addition, criteria such as the opening of the mouth, protrusion of the mandible, body mass and, most important, history of difficult intubation are used to predict difficult intubation [5,6]. MP is widely used and bedside applicable method, but it is subjective due to interobserver variations $[\mathbf{7 , 8}]$.

Nose varies in size and shape according to races and individuals, it is an olfactory and respiratory organ. Turkey's Eastern Black Sea Region, the inhabitants of that area the size of the nose is known as different from people in other parts of Turkey. 
In this region, we also observed a higher incidence of difficult intubation in humans with typical nose structure. Therefore, in this study, we designed to investigate whether there is a relationship between difficult intubation and the structure of the nose in this region.

For this investigation, we created a scale defining the shape and size of nose by calculating the distance between the radix nasii and nasal tip and then comparing it to the distance between the alar cartilage domes. The resulting scale was compared with TRMD and SMD distances and MP classification in terms of predicting the difficulty of intubation determined by the Cormack-Lehane (CL) classification.

\section{Materials and methods}

The study was conducted at the Research Hospital of the University of Rize in the North-Eastern region of Turkey. After obtaining approval from the University of Rize Medical School Ethics Committee and after obtaining written informed consent, patients scheduled for elective surgery (abdominal, urologic, endocrinologic) requiring endotracheal intubation between January and November 2010 were enrolled in the study. Patients older than 18 years of age and having a physical ASA score of I-III were included in the study. Emergency and obstetrics cases, patients with a history of nasal trauma, nasal operation or airway anomaly, and patients lacking teeth were excluded from study. A total of 500 patients (300 females and 200 males) fulfilling these criteria were enrolled in the study.

During the preoperative visit, patient characteristics such as age, gender, weight and height were recorded. The MP score, TRMD, SMD, NS (the distance between radix nasi and nasal tip, and the distance between the alar cartilage domes) were measured with a ruller and recorded by the same anesthesiologist.

\section{MP assessment}

Patients were placed in a sitting position, with their head in a neutral position, mouth fully open, and tongue protruded maximally, with no phonation and at an eye-to-eye position with the examiner. MP classification is scored according to classical definition $[\mathbf{5 , 9}, \mathbf{1 0}]$.

\section{SMD assessment}

The SMD was measured in the supine position with the fully extension of head and the mouth closed. The distance between the upper border of the manubrium sterni and the bony point of the mentum was measured in centimeters $[6,10]$.

\section{TRMD assessment}

For TRMD, the direct distance between the upper border of the thyroid cartilage and the bony point of mentum was measured $[6,11]$.

\section{NS assessment}

The longitudinal distance (distance between radix nasii and the nasal tip) and the vertical distance (distance between the nasal domes) were measured as shown in (Figure 1). The nasal scale score was calculated by dividing the longitudinal distance by the vertical distance and expressed as a number within a range of 1.22 to 2.3. Difficult intubation was defined as a nasal score of lower than 1.4 as derived from the ROC analysis of the results. Difficult intubation prediction criteria was classified as three (soft and hard palate clearly visible) and four points (only hard palate visible) in the MP classification $[5,10]$, a SMD of less than $13 \mathrm{~cm} \mathrm{[10],} \mathrm{TRMD} \mathrm{of} \mathrm{less} \mathrm{than} 6.5 \mathrm{~cm} \mathrm{[11],} \mathrm{and} \mathrm{for} \mathrm{NS}$ lower than 1.4.

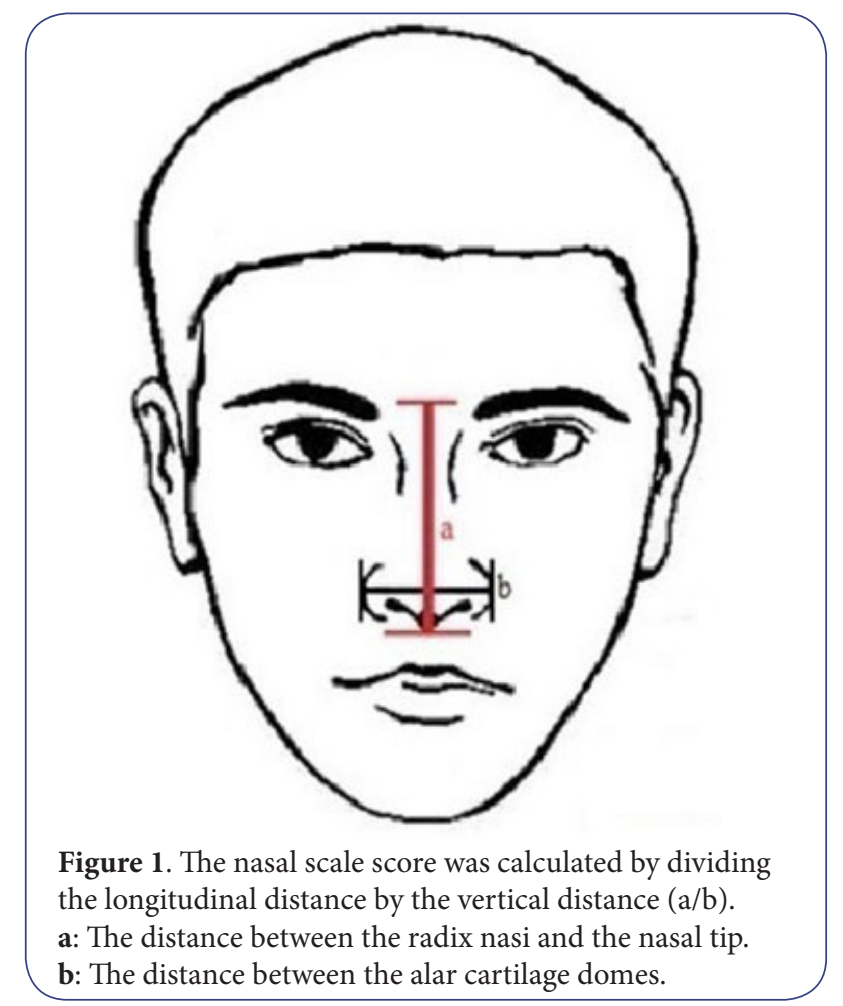

Patients were induced with 2-3 mg kg-1 propofol and $1 \mu \mathrm{g} \mathrm{kg}$ fentanyl. Neuromuscular blockage was obtained with $0.1 \mathrm{mg}$ $\mathrm{kg}^{-1}$ vecuronium. Neuromuscular function was assessed by train-of-four (TOF) stimulation of the ulnar nerve, using TOFWatch $^{\circledR}$ (Organon Teknika, The Netherlands) after anesthesia induction. Direct laringoscopy was applied when a TOF ratio of 0 was obtained. With the neck in flexion and head extension, laryngoscopy was applied with either Macintosh blade size three or four by same attending anesthesiologist with significant airway experience. During laryngoscopy, the CL class of the patient was recorded and three (Only epiglottis visible) and four (Epiglottis not visible) points in Cormack-Lehane classification was accepted as difficult intubation $[11,12]$.

\section{Statistical analysis}

The presence of any difference between diagnostic tests and real results (Cormack-Lehane) was analyzed using the McNemar chi-square test to detect the judgment abilities, i.e., the performance of diagnostic tests. In evaluation according to gender; 
Pearson's Chi Square test was used to test and Yates Continuity Correction. Predictive incidences of NS, TRMD, MP and SMD Specificity ratio in the evaluation of the " $t$ test of the difference between the two ratios (ratio differance Two group t test)" was used. Cormack-Lehane by the other variables AUROC values were determined by ROC curve analysis. All statistical analysis was performed using the statistical package for social sciences 18.0 (SPSS Inc., Chicago, IL, USA) with a two-tailed P-value of 0.05 used as a threshold for significance. Results at $95 \%$ confidence interval, significance at $\mathrm{p}<0.05$ level were evaluated.

The following parameters were calculated to evaluate the performance of the predictive tests compared with CormackLehane: sensitivity, specificity, positive predictive value, negative predictive value, false positive, false negative and accuracy. Values were calculated according to the following formulae:

Sensitivity $=$ True positives $/$ (True positives + False negatives $)$ Specificity $=$ True negatives $/$ (True negatives + False positives) Positive predictive value $=($ SensitivityxPrevelance $) /$ [(SensitivityxPrevelance $)+(1$-Specificity $) \times(1$-Prevelance $)]$ Negative predictive value $(\mathrm{NPV})=[$ Specificityx $(1$-Prevelance $)]$ /[(1-Sensitivity)xPrevelance+Specificityx(1-Prevelance)] False positive $=(1-$ Specificity $)$

False negative $=(1-$ Sensitivity $)$

Accuracy $=($ True positives + True negatives $) /($ True positives + True negatives + False positives + False negatives).

\section{Results}

A total of 500 patients were enrolled in the study, there were no dropouts. The frequency of difficult intubation was predicted to be higher for males than for females by the NS and MP classification $(\mathrm{p}<0.05)$, (Table 1). Difficult intubation was found not to be related to age (mean: 43.91, SEM: 0.6$)$ or body mass index (mean: 26.36, SEM: 0.17), ( $\mathrm{p}>0.05)$.

The frequency of difficult intubation was found to be $12.4 \%$ by
CL. Prediction of difficult intubation by MP was $12 \%$, SMD was $31.8 \%$, TRMD was $14.4 \%$ and by NS was $9.4 \%$. NS, TRMD and MP were similar for difficult intubation predictions compared with CL ( $p>0.05$ ), (Table 2). SMD showed greater variation in terms of difficult intubation predictions compared with CL $(\mathrm{p}<0.05)$.

Evaluation of NS was done by further analysis. The best cut-off value for the ROC curve analysis was calculated as 1.4 as explained in detail in the materials and methods section, meaning that values below 1.4 were considered as difficult intubation predictor.

Table 3 shows the sensitivity, specificity, positive predictive, negative predictive, false positive, false negative and accuracy values of NS, TRMD, SMD and MP classifications compared with CL classification. The accuracy of NS (85.8\%) was higher than SMD and TRMD (69\% and $82.8 \%$, respectively) and lower than MP (96\%). These results show that MP has the highest

Table 1. Distribution of difficult intubation frequency according to sex of the patients.

\begin{tabular}{lllll}
\hline & Male & Female & Total & P \\
& N (\%) & N (\%) & N (\%) & \\
\hline Cormack-Lehane & & & \multicolumn{2}{c}{$<0.001$} \\
$\begin{array}{l}\text { Difficult intubation } \\
\text { Non-difficult intubation }\end{array}$ & $158\left(67.7^{*}\right)$ & $20(32.3)$ & $62(100)$ & \\
\hline Mallampati & $280(63.9)$ & $438(100)$ & \\
Difficult intubation & $38\left(63.3^{*}\right)$ & $22(36.7)$ & $60(100)$ & \\
Non-difficult intubation & $162(36.8)$ & $278(63.2)$ & $440(100)$ & \\
\hline Nasal scale & & & & 0.001 \\
Difficult intubation & $27\left(57.4^{*}\right)$ & $20(42.6)$ & $47(100)$ & \\
Non-difficult intubation & $173(38.2)$ & $280(61.8)$ & $453(100)$ & \\
\hline
\end{tabular}

*The effect of gender to predicted difficult intubation is analysed using Chi-square test and Yates Continuity Correction test $(\mathrm{p}<0.01 ; \mathrm{p}<0.05)$.

Table 2. Comparison of NS, TMD, SMD and MP test performances with Cormack-Lehane performance.

\begin{tabular}{|c|c|c|c|c|}
\hline & \multicolumn{2}{|r|}{ CL } & \multirow{3}{*}{$\begin{array}{l}\text { Total } \\
\text { N (\%) }\end{array}$} & \multirow{3}{*}{$\begin{array}{l}\text { Statistics } \\
\text { (McNemar } \\
\text { P value) }\end{array}$} \\
\hline & Difficult & Non difficult & & \\
\hline & \multicolumn{2}{|l|}{$\mathbf{N}(\%)$} & & \\
\hline NS & & & & 0.096 \\
\hline Difficult intubation & $19(30.6)$ & $28(6.4)$ & $47(9.4)$ & \\
\hline Non-difficult intubation & $43(69.4)$ & $410(93.6)$ & $453(90.6)$ & \\
\hline TRMD & & & & 0.332 \\
\hline Difficult intubation & $24(38.7)$ & $48(11)$ & $72(14.4)$ & \\
\hline Non-difficult intubation & $38(61.3)$ & $390(89)$ & $428(85.6)$ & \\
\hline SMD & & & & $<0.001$ \\
\hline Difficult intubation & $33(53.2)$ & $126(28.8)$ & $159(31.8)$ & \\
\hline Non-difficult intubation & $29(46.8)$ & $312(71.2)$ & $341(68.2)$ & \\
\hline Mallampati & & & & 0.824 \\
\hline Difficult intubation & $51(82.3)$ & $9(2.1)$ & $60(12)$ & \\
\hline Non-difficult intubation & $11(17.7)$ & $429(97.9)$ & $440(88)$ & \\
\hline Total & $62\left(12.4^{*}\right)$ & $438\left(87.6^{*}\right)$ & $500(100)$ & \\
\hline
\end{tabular}

${ }^{\star}$ Row percent, all others are column percent. 
Table 3. Predictive incidences of NS, TRMD, MP and SMD measurements with the CL laryngeal view classification.

\begin{tabular}{llllllll}
\hline & $\begin{array}{l}\text { False positive } \\
(\%)\end{array}$ & $\begin{array}{l}\text { False negative } \\
(\%)\end{array}$ & $\begin{array}{l}\text { Sensitivity } \\
(\%)\end{array}$ & $\begin{array}{l}\text { Specificity } \\
(\%)\end{array}$ & $\begin{array}{l}\text { Positive } \\
\text { predictive } \\
\text { value (\%) }\end{array}$ & $\begin{array}{l}\text { Negative } \\
\text { predictive } \\
\text { value (\%) }\end{array}$ & $\begin{array}{l}\text { Accuracy } \\
(\%)\end{array}$ \\
\hline NS $(\leq 1.4 \mathrm{~cm})$ & 6.4 & 69.4 & 30.6 & 93.6 & 40.4 & 90.5 & 85.8 \\
TRMD $(\leq 6.5 \mathrm{~cm})$ & 11 & 61.3 & 38.7 & 89 & 33.3 & 91.1 & 82.8 \\
$\mathrm{SMD}(\leq 12.5 \mathrm{~cm})$ & 28.8 & 46.8 & 53.2 & 71.2 & 20.8 & 91.5 & 69 \\
$\begin{array}{l}\text { Mallampati } \\
\text { (grade III/ IV) }\end{array}$ & 2.1 & 17.7 & 82.3 & 97.9 & 85 & 97.5 & 96 \\
\hline
\end{tabular}

sensitivity (82.3\%) and specificity (97.9\%), which is represented in the ROC curve in (Figure 2). NS (Table 4) has the worst sensitivity (30.6\%) but the second highest specificity (93.6\%).

Table 5 shows the patients that are predicted as difficult intubation according to the predictive tests, and those who demonstrated really difficult intubation. Also depicts the number of patients that are not evaluated as difficult intubation, but revealed difficult during intubation.

\section{Discussion}

Patients scheduled for general anesthesia may present with difficulty at intubation. Preanesthetic examination of the airways is the utmost important in assessing the risk of difficult intubation. MP classification, TRMD, SMD, mouth opening, protrusion of the mandible, position and size of teeth, stability and elasticity of the atlanto-occipital joint are still used to evaluate the airway during the preoperative visit $[\mathbf{5 , 6}$. Depending on the many patient characteristics and circumstances, difficulty and delay at intubation may cause or increase risks of hypoxia, hypercarbia, direct airway trauma, brain damage and myocardial cell damage [13-15]. These risks can be lowered by predicting the difficulty

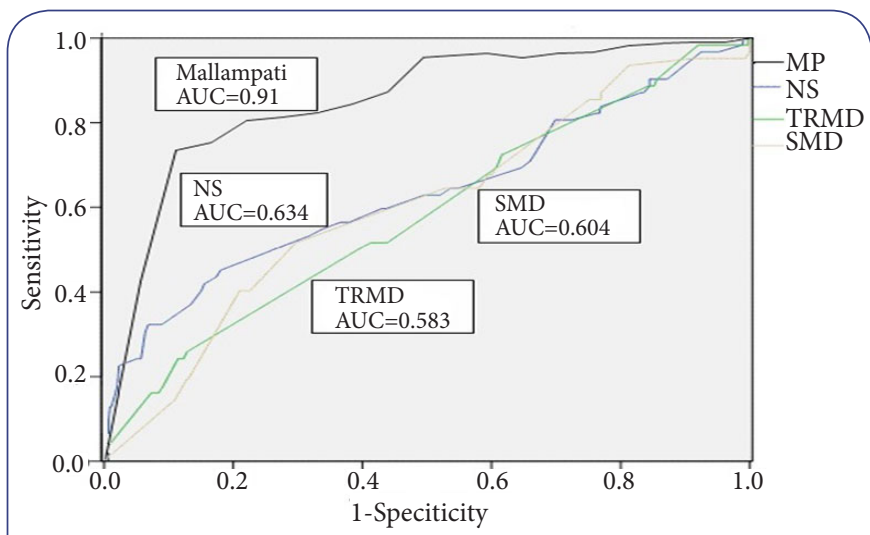

Figure 2. Summary receiver operating characteristic curve analysis of four different bedside screening tests for difficult intubation. Comparisons of ROC curve of NS, MP, TRMD and SMD tests performances with Cormack-Lehane. Areas under the curve (AUC) for NS, MP, TRMD and SMD were $0.634(\mathrm{p}=0.001), 0.910(\mathrm{p}=0.001) ; 0.583(\mathrm{p}=0.009)$ and 0.604 $(\mathrm{p}=0,007)$ respectively after $\mathrm{ROC}$ analysis.
Table 4. Area under curve.

\begin{tabular}{|c|c|c|c|c|c|}
\hline \multicolumn{6}{|c|}{ Area Under the Curve (Cormack-Lehane) } \\
\hline & \multirow[t]{2}{*}{ Area } & \multirow[t]{2}{*}{ Std. Error(a) } & \multirow[t]{2}{*}{$\mathbf{P}$} & \multicolumn{2}{|c|}{$\begin{array}{l}\text { 95\% Confidence } \\
\text { Interval }\end{array}$} \\
\hline & & & & Upper & Lower \\
\hline Mallapati & 0.910 & 0.027 & $<0.001$ & 0.837 & 0.943 \\
\hline NS & 0.634 & 0.044 & $<0.001$ & 0.550 & 0.721 \\
\hline TRMD & 0.583 & 0.034 & 0.009 & 0.498 & 0.690 \\
\hline SMD & 0.604 & 0.040 & 0.007 & 0.531 & 0.687 \\
\hline
\end{tabular}

Table 5. Patients that are predicted as difficult intubation according to the tests, those who demonstrated true difficult intubation and the number of patients that are not evaluated as difficult intubation, but revealed difficulty during intubation according to the tests.

\begin{tabular}{lllll}
\hline $\begin{array}{l}\text { Airway assessment } \\
\text { test and difficult } \\
\text { intubation criteria }\end{array}$ & PDIT $^{\star}$ & PDITT $^{\star *}$ & PDITF $^{\star * *}$ & $\begin{array}{l}\text { Total number } \\
\text { of patients }\end{array}$ \\
\hline NS $\leq 1.4$ & 47 & 19 & 43 & 500 \\
SMD $\leq 13$ & 139 & 33 & 29 & 500 \\
TMD $\leq 6.5$ & 72 & 24 & 38 & 500 \\
$\begin{array}{l}\text { Mallampati } \\
\text { grade III/ IV) }\end{array}$ & 60 & 51 & 11 & 500 \\
$\begin{array}{l}\text { Cormack-Lehane } \\
\text { classification } \\
\text { grade III/ IV) }\end{array}$ & 62 & 62 & 0 & 500 \\
\hline
\end{tabular}

*PDIT: Patients are predicted as difficult intubation according to the predictive tests.

**PDITT: Patients are predicted as difficult intubation according to the predictive tests, and those who demonstrated really difficult intubation.

***PDITF: Patients are not difficult intubation according to the predictive tests, but revealed difficulty during intubation.

at intubation, thereby allowing for more planning and the appropriate preparation of required equipment [16].

In this study, the incidence of difficult intubation with MP was $12 \%$ and its sensitivity, specificity, positive predictive value and negative predictive values were $82.3 \%, 97.9,85$ and 97.5, respectively. This difficult intubation incidence is different than the seen in literature [17]. We considered that this difference 
might be the reason of different anatomical structures of head and neck of those people living in the region where the study was performed. In this study MP appeared to be the best test among the others in regard to sensitivity and specificity. No single airway test can provide a high index of sensitivity and specificity for prediction of difficult airway. Therefore MP is recommended to be used in combination with other tests [18].

The nose develops from the pharyngeal arcus, which is the stem of the neck, mandible and face [19]. The methodology of MP classification, TRMD and SMD tests are originated from the anatomical structure of oropharynx and neck; therefore, it is possible that its dimensions and anatomical shape may correlate well with the nasopharynx and neck that form the airway such as the distances measured for the new nasal scale (NS) evaluation. The NS that has the sensitivity, specificity, positive predictive value and negative predictive values of $30.6 \%, 93.6 \%$, $40 \%$ and $90.5 \%$ respectively, can be used in combination with MP along with TRMD and SMD in clinical practice as the new assessment test for difficult intubation.

Ethnic groups have varying nasal dimensions [19]. This study investigated nasal proportion in the north-eastern region of Turkey, which contains several ethnic groups. The possible differences of nasal proportions between these ethnic groups may be the subject of a separate study. Because of the racial differences the anatomical criteria previously established might be considered to vary from one society to others. In literature, the incidence of difficult intubation with SMD and TRMD found more variable in the different region of world and different ethnicity. NS is totally based on the anatomic structure of nose, so in different ethnic group, as the region that our study conducted, the prediction of difficult intubation with NS might be differed. Therefore, for the NS, as well as SMD and TRMD, the performance of this test needs to be explored in the different races and societies with a larger number of subjects.

Moreover, some studies suggest that body mass index should be a criteria of difficult intubation [20], but this view is not held universally [21]. The results of this study showed no correlation between body mass index and difficulty at intubation. Our NS independent of the body mass index can predict difficult intubation.

Consequently, we showed that the sensitivity of NS is lower as compared with TMD, SMD and MP. However; the results also showed that NS has higher specificity than TMD and SMD but lower than MP. The NS is an objective test that can be easily applied by the bedside. We recommend using the NS for routine clinical practice. NS could be an indicator for difficult tracheal intubation.

NS was chosen from authors' observation, the chance of bias for difficult intubation could not be ruled out because intubation was not performed by independent anesthesiologist, racial and geographical variation of nasal scale will be present. The study was a single center observation and need multicentric research to have wider application for airway assessment.

\section{Conclusions}

The NS is an objective and specific test that can be easily applied by the bedside, which can supplement the existing tests. Limitations of the study are NS races and may vary between individuals. Its usability in different ethnic populations presenting with different face and nose shapes should be investigated further.

\section{Competing interests}

The authors declare that they have no competing interests.

\section{Authors' contributions}

Dr. Habib Bostan, Dr. Yakup Tomak and Dr. Basar Erdivanli attests to the integrity of the original data and the analysis reported in this manuscript. All authors helped to data collection, conduct the study and designing of the study.

\section{Publication history}

Editors: Sambhunath Das, All India Institute of Medical Sciences (AIIMS), India.

Dario Galante, University Hospital "Ospedali Runiti” of Foggia, Italy. Received: 11 February 2015 Revised: 19 March 2015

Accepted: 30 March 2015 Published: 31 March 2015

\section{References}

1. Cattano D, Panicucci E, Paolicchi A, Forfori F, Giunta F and Hagberg C. Risk factors assessment of the difficult airway: an italian survey of 1956 patients. Anesth Analg. 2004; 99:1774-9. | Article | PubMed

2. Rocke DA, Murray WB, Rout CC and Gouws E. Relative risk analysis of factors associated with difficult intubation in obstetric anesthesia. Anesthesiology. 1992; 77:67-73. | Article | PubMed

3. Randell T. Prediction of difficult intubation. Acta Anaesthesiol Scand. 1996; 40:1016-23. | PubMed

4. Shiga T, Wajima Z, Inoue $T$ and Sakamoto A. Predicting difficult intubation in apparently normal patients: a meta-analysis of bedside screening test performance. Anesthesiology. 2005; 103:429-37. | Article | PubMed

5. Mallampati SR, Gatt SP, Gugino LD, Desai SP, Waraksa B, Freiberger D and Liu PL. A clinical sign to predict difficult tracheal intubation: a prospective study. Can Anaesth Soc J. 1985; 32:429-34. I PubMed

6. Savva D. Prediction of difficult tracheal intubation. Br J Anaesth. 1994; 73:149-53. | $\underline{\text { Pdf }}$ | PubMed

7. Lee RA, van Zundert AA, Maassen RL, Willems RJ, Beeke LP, Schaaper $\mathrm{JN}$, van Dobbelsteen J and Wieringa PA. Forces applied to the maxillary incisors during video-assisted intubation. Anesth Analg. 2009; 108:18791. | Article | PubMed

8. Meléndez H.J, D. Leal and D. Ramírez. Agreement between the objective and subjective evaluation for predicting and finding a difficult airway. Rev. Col. Anest. 2010; 38:34-49.

9. Mashour GA, Kheterpal S, Vanaharam V, Shanks A, Wang LY, Sandberg WS and Tremper KK. The extended Mallampati score and a diagnosis of diabetes mellitus are predictors of difficult laryngoscopy in the morbidly obese. Anesth Analg. 2008; 107:1919-23. | Article I PubMed

10. Samsoon GL and Young JR. Difficult tracheal intubation: a retrospective study. Anaesthesia. 1987; 42:487-90. | Article | PubMed

11. Khan ZH, Mohammadi M, Rasouli MR, Farrokhnia F and Khan RH. The diagnostic value of the upper lip bite test combined with sternomental distance, thyromental distance, and interincisor distance for prediction of easy laryngoscopy and intubation: a prospective study. Anesth Analg 2009; 109:822-4. | Article | PubMed

12. Cormack RS and Lehane J. Difficult tracheal intubation in obstetrics. Anaesthesia. 1984; 39:1105-11. I Article I PubMed

13. Cook TM, Woodall N and Frerk C. Major complications of airway 
Bostan et al. Journal of Anesthesiology \& Clinical Science 2015,

management in the UK: results of the Fourth National Audit Project of the Royal College of Anaesthetists and the Difficult Airway Society. Part 1: anaesthesia. Br J Anaesth. 2011; 106:617-31. | Article | PubMed

14. El-Orbany $M$ and Woehlck HJ. Difficult mask ventilation. Anesth Analg. 2009; 109:1870-80. | Article | PubMed

15. Saxena S. The ASA difficult airway algorithm: is it time to include video laryngoscopy and discourage blind and multiple intubation attempts in the nonemergency pathway? Anesth Analg. 2009; 108:1052. | Article | PubMed

16. Lee A, Fan LT, Gin T, Karmakar MK and Ngan Kee WD. A systematic review (meta-analysis) of the accuracy of the Mallampati tests to predict the difficult airway. Anesth Analg. 2006; 102:1867-78. | Article | PubMed

17. Gupta S, KR, Rajesh Sharma and Jain D. Airway Assessment: Predictors of Difficult Airway. Indian J. Anaesth. 2005; 49:257-262.

18. Carstens MH. Development of the facial midline. J Craniofac Surg. 2002; 13:129-87; discussion 188-90. | PubMed

19. Leong SC and Eccles R. Race and ethnicity in nasal plastic surgery: a need for science. Facial Plast Surg. 2010; 26:63-8. | Article | PubMed

20. Al Ramadhani S, Mohamed LA, Rocke DA and Gouws E. Sternomental distance as the sole predictor of difficult laryngoscopy in obstetric anaesthesia. Br J Anaesth. 1996; 77:312-6. | Pdf | PubMed

21. Oates JD, Macleod AD, Oates PD, Pearsall FJ, Howie JC and Murray GD. Comparison of two methods for predicting difficult intubation. $\mathrm{BrJ}$ Anaesth. 1991; 66:305-9. | Pdf | PubMed

\section{Citation:}

Bostan H, Tomak Y, Erdivanli B and Karaoglu L. Nasal scale: a novel supplemental preoperative airway assessment technique. J Anesthesiol Clin Sci. 2015; 4:8. http://dx.doi.org/10.7243/2049-9752-4-8 